\title{
EXPERIMENTAL TESTING OF TWO NOVEL STRESS SENSORS FOR SHM OF MASONRY STRUCTURES
}

\author{
L. LA MENDOLA ${ }^{1}$, M.C. ODDO ${ }^{1}$, M. PAPIA ${ }^{1}$, F. PAPPALARDO ${ }^{2}$, A. PENNISI ${ }^{2}$, G. \\ BERTAGNOLI $^{3}$, F. DI TRAPANI ${ }^{3 *}$, A. MONACO $^{4}$, F. PARISI $^{5}$, S. BARILE $^{6}$ \\ ${ }^{1}$ Engineering Department, University of Palermo, Italy \\ e-mail: \{lidia.lamendola, mariaconcetta.oddo01, maurizio.papia\}@unipa.it, www.unipa.it \\ ${ }^{2}$ STMicroelectronics S.r.l., System Research and Application, Catania, Italy \\ e-mail: \{francesco.pappalardo, agatino.pennisi\}@ st.com, www.st.com
}

$3^{*}$ Department of Structural, Geotechnical and Building Engineering, Politecnico di Torino, Turin, Italy e-mail: fabio.ditrapani@ polito.it, www.polito.it (*corresponding author)

${ }^{3}$ Department of Structural, Geotechnical and Building Engineering, Politecnico di Torino, Turin, Italy e-mail: gabriele.bertagnoli@ polito.it, www.polito.it

${ }^{4}$ Department of Architecture and Design, Politecnico di Torino, Turin, Italy e-mail: alessia.monaco@polito.it, www.polito.it

${ }^{5}$ Department of Structures for Engineering and Architecture, University of Naples Federico II, Naples, Italy e-mail: fulvio.parisi@unina.it, www.unina.it

${ }^{6}$ Mapei S.p.A., Milan, Italy

e-mail: s.barile@mapei.it, www.mapei.com

Keywords: Structural health monitoring; unreinforced masonry walls; piezoelectric stress sensors; capacitive stress sensors; experimental testing.

Abstract. The paper presents an experimental study on the performance of two types of stress sensor for their possible use in structural health monitoring (SHM) of masonry constructions. Ceramic piezoelectric sensors and capacitive sensors were installed in mortar bed-joints of two series of masonry specimens made of calcarenite stones and clay bricks. The specimens were tested under uniaxial compression, assessing the effectiveness of the sensors in recording the stress state variation in terms of vertical stresses within different types of masonry. Experimental results show that, although both the ceramic and capacitive sensors were initially designed to be embedded in concrete elements, their application in mortar joints ensures a good agreement with records by standard measurement devices. Results also demonstrate the possibility to extend the application of these devices to existing masonry structures, where SHM becomes a challenging issue. 


\section{INTRODUCTION}

Recent natural disasters and aging-related damage of structural elements and materials have pointed out that an adequate diagnostic system is required to detect relevant changes in structural behavior that can potentially affect safety of a structure [1-3]. A permanent monitoring system can be useful to reveal damage and its propagation, supporting decisionmaking to keep safety levels above prescribed thresholds. The idea of monitoring new and existing structures, if applied over a large territorial scale, can produce significant advantages [4-6] in controlling safety of strategic and residential buildings, which many times have masonry primary structures, especially in historic cities. In last years, the evolution of low-cost sensors derived from telecommunication industry, the development of high-speed Internet communication, the advent of cloud-based computing and of big data platforms making use of artificial intelligence, provided a new enhanced scenario for structural health monitoring (SHM). This kind of monitoring has been implemented using different devices, such as contactless sensors with high-resolution cameras, drones and contact robotic sensors [7]. Sensing technology is largely employed in the field of automotive and aerospace engineering. On the contrary, SHM has been rarely applied in structural and infrastructure engineering for a long time, because of the instrumentation costs, uncertain possibility to ensure long-term monitoring, complexity of the installation, and sometimes a difficult interpretation of results.

Recently, special attention has been paid to new-generation low-cost sensors, based on

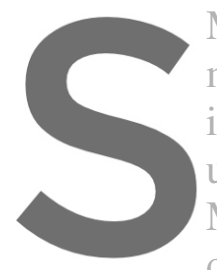
Micro Electro-Mechan

movements of microm tim inclinometers, acceleron

used to support the cond

MEMS technology,

delineate an emerging
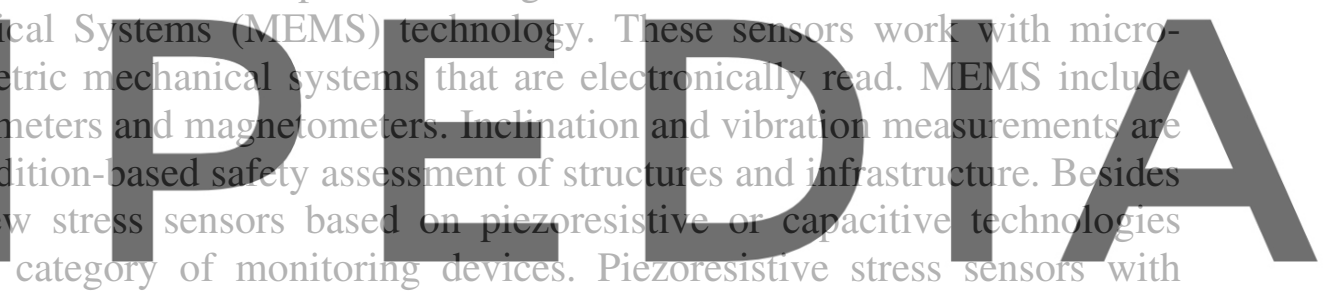

ceramic sensing package have been already used imbedded in concrete structures, while

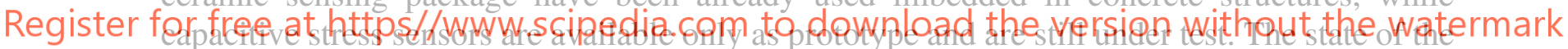

art enhances the optimization of the sensors' layout for health monitoring of new structures by

incorporating a sensor network that has been already designed [8]. Both the sensors are thought to be used in new and existing structures although with different modalities of installation.

The current paper presents two innovative monitoring devices [9] which are tested for their possible implementation within unreinforced masonry structures. The proposed devices are piezoresistive and capacitive, low-cost, stress sensors. Capacitive sensors provide a sensing ceramic package working with the deformation of piezoresistive elements arranged on the ceramic plate. Capacitive sensor consists of two conductive plates with a thin dielectric foil between them. The capacitance, measured in picofarads $(\mathrm{pF})$, changes with the variation of distance between the plates subject to vertical strains. The experimental program has been carried out on calcarenite and clay brick masonry wall specimens was addressed to test the capacity of the sensors to reveal strain variations. Data recorded by the sensors have been compared to those provided by a standard (reference) measuring device. 


\section{PROPOSED CERAMIC AND CAPACITVE SENSORS}

The ceramic sensors tested in the experimental campaign include embedded electronic circuits as shown in Figure 1a, which are based on a microcontroller with embedded memory flash to read the low electrical signal of piezoresistive bridges and to convert the electrical signal into a digital value. Since ceramic is a perfectly elastic material, a direct calculation of the stress in a given direction is possible in the field of the elastic service stresses without any direct measure of deformation. The sensor was initially designed to be embedded inside concrete casting tied to the rebars. Its application within concrete structures under short-term loading is discussed in [10-12]. In a second experimental campaign the sensor was tested under long-term loading [13]. The effectiveness of these sensors to be employed within masonry mortar joints is explored in the current paper, providing also details about installation modalities.
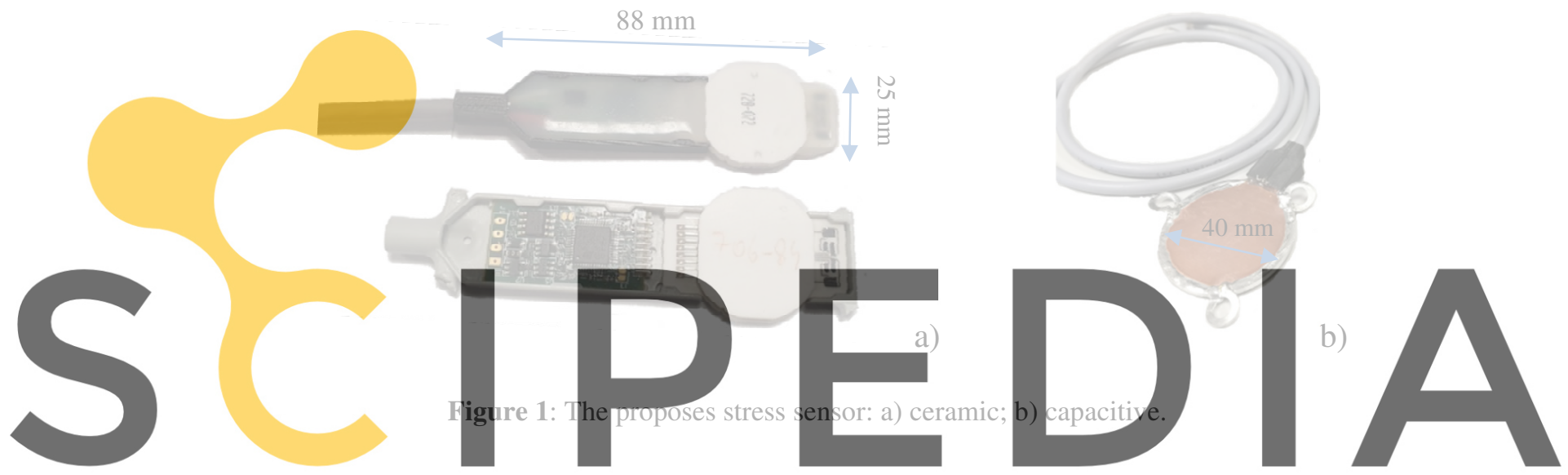

A new capacitive stress sensor [14] is also proposed and tested in the paper for the same

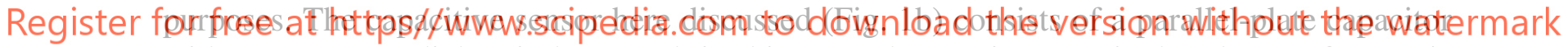
with Kapton as a dielectric layer and, in this case, the sensing area is the plate surface. It is noteworthy observing that, the sensing surface can be realized as big as needed to be comparable with the dimensions of the wall. The capacitance, $\mathrm{C}$, of a parallel plate capacitor is given by the following expression:

$$
C=\frac{\varepsilon A}{d}
$$

where $\varepsilon, A$ and $d$ are the permittivity of the gap, the area of electrodes, and the gap between the electrodes, respectively. The dielectric used in the sensor is the Kapton, which has a dielectric constant value $\varepsilon_{r}=3.4$. The variation of the capacitance is related to the variation in strain according to the variation of the distance between the electrode plates. The sensor reader is a signal conditioning electronics which converts the capacitance signal to voltage, current or frequency. The reader used for capacitive sensors makes use of a microcontroller and it is located outside the sensing part. Capacitive sensors offer different advantages including high sensitivity, high stability, low temperature sensitivity, low production costs and durability. 


\section{EXPERIMENTAL TESTING OF SENSORS IN MASONRY WALLS}

The experimental program consisted of twelve specimens. Six of them were made of calcarenite bricks extracted from Sabucina quarry (Southern Italy). The other six specimens were made of solid clay bricks. Calcarenite and clay bricks had bricks had the same size of $250 \times 120 \times 50 \mathrm{~mm}^{3}$. The compressive strength the bricks was also experimentally obtained by compressive tests carried out according to UNI EN 1926 [15] and UNI EN 772 [16], respectively. In detail compressive tests were carried out on six cubes of calcarenite and six cubes of clay with side of 100 and $50 \mathrm{~mm}$, respectively. The average compressive strengths obtained from the tests were 11.80 MPa and 23.39 MPa for calcarenite stones and clay bricks, respectively. All specimens were fabricated with a premixed cementitious mortar an average compressive strength of $8.36 \mathrm{MPa}$. Each specimen was made by seven rows of clay or calcarenite units $\left(250 \times 120 \times 50 \mathrm{~mm}^{3}\right)$ and interposed mortar joints having a thickness of $10 \mathrm{~mm}$.

Capacitive and ceramic sensors were pre-installed within the specimens during their

construction according to three patterns shown in Figure 2, which are also summarized in Table.
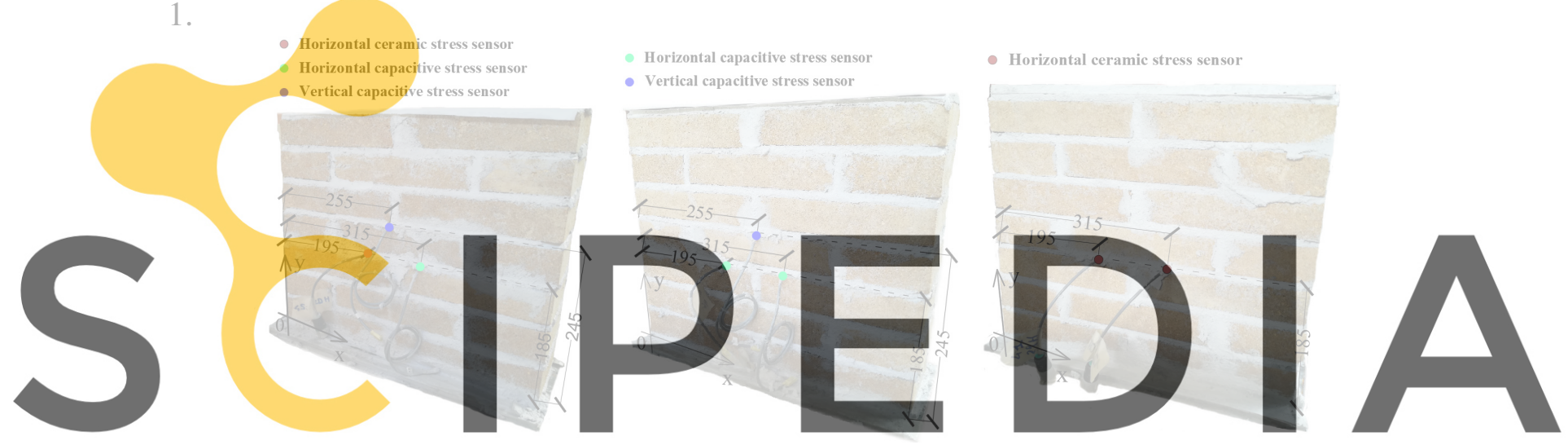

(a)

(b)

(c)

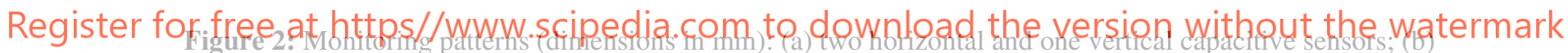

two horizontal stress sensors (one ceramic and one capacitive) and one additional vertical capacitive sensor; (c) two horizontal ceramic sensors.

Table 1: Specimens and sensors setups.

\begin{tabular}{|c|c|c|}
\hline $\begin{array}{c}\text { ID } \\
\text { sample }\end{array}$ & $\begin{array}{c}\begin{array}{c}\text { Masonry } \\
\text { type }\end{array} \\
\end{array}$ & $\begin{array}{c}\text { Sensors } \\
\text { Set-up }\end{array}$ \\
\hline SP1_C & \multirow{6}{*}{ Calcarenite } & \multirow{2}{*}{2 horizontal capacitive stress sensors } \\
\hline SP2_C & & \\
\hline SP3_C & & \multirow{2}{*}{$\begin{array}{c}1 \text { horizontal capacitive stress sensor } \\
+ \\
1 \text { horizontal ceramic stress sensor }\end{array}$} \\
\hline SP4_C & & \\
\hline SP5_C & & \multirow{2}{*}{2 horizontal ceramic stress sensors } \\
\hline SP6_C & & \\
\hline SP1_L & \multirow{6}{*}{ Clay } & \multirow{2}{*}{2 horizontal capacitive stress sensors } \\
\hline SP2_L & & \\
\hline SP3_L & & \multirow{2}{*}{$\begin{array}{c}1 \text { horizontal capacitive stress sensor } \\
+ \\
1 \text { horizontal ceramic stress sensor }\end{array}$} \\
\hline SP4_L & & \\
\hline SP5_L & & \multirow{2}{*}{2 horizontal ceramic stress sensors } \\
\hline SP6_L & & \\
\hline
\end{tabular}


In detail, sensors were installed in the mortar bed joints close to the mid-height of each specimen (Figure 2). The three different measuring patterns provided: two capacitive stress sensors in SP1 and SP2 specimens; two ceramic stress sensors in SP5 and SP6 specimens; one ceramic and one capacitive stress sensor in SP3 and SP4 specimens. Capacitive sensors were also installed in vertical joints but the results from these sensors will not be commented in this paper.

Figure 3 shows the positioning phases of ceramic and capacitive sensors within the mortar joints. This phase was crucial as it was necessary to place sensors avoiding any type of rotation and translation.

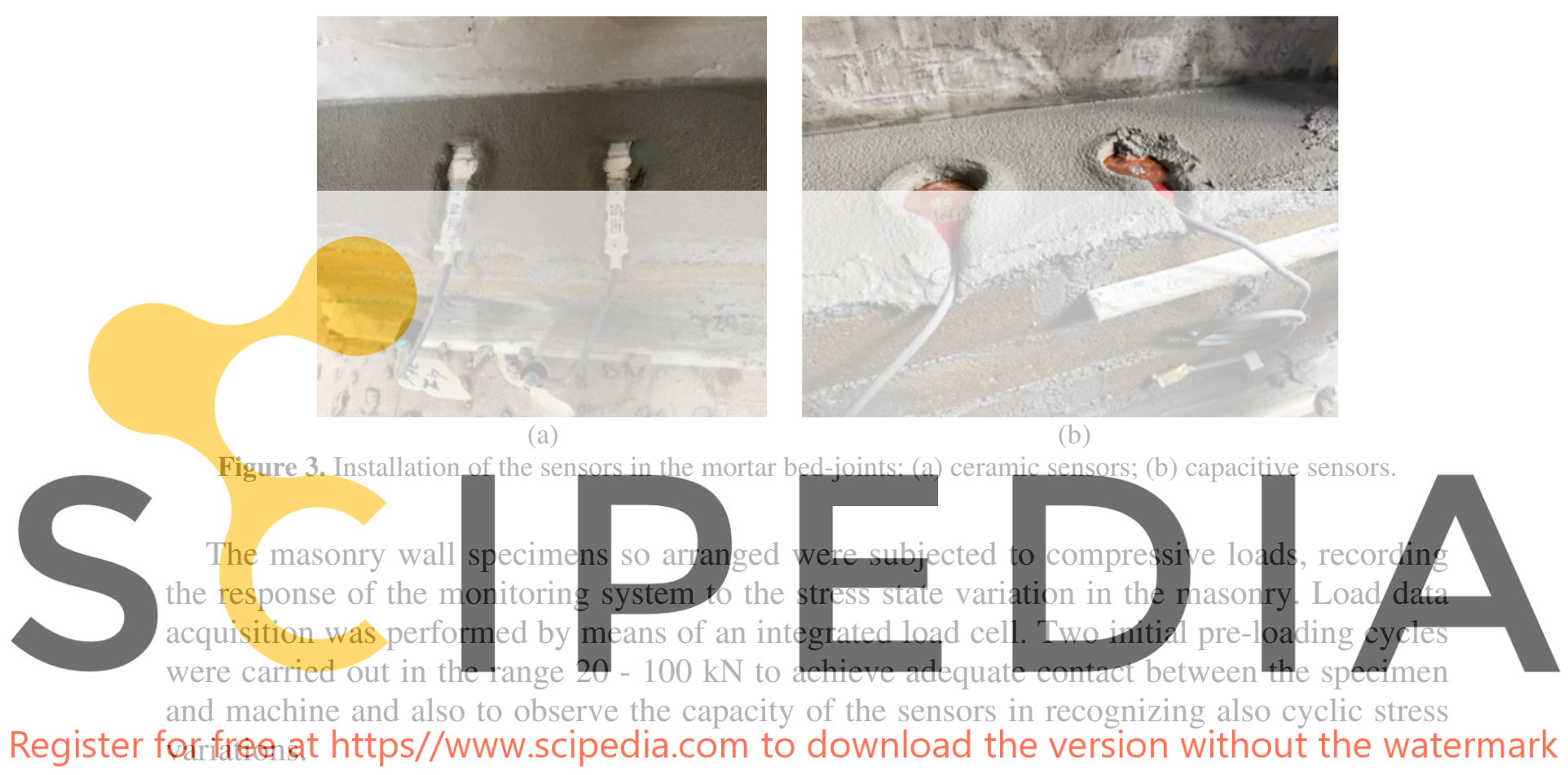

\section{EXPERIMENTAL RESULTS}

\subsection{Results by ceramic sensors}

For the sake of space, a reduced number of results are presented in the paper. Figures $4 \mathrm{a}$ and $4 \mathrm{~b}$ show the experimental results for calcarenite and clay brick masonry specimens equipped with ceramic stress sensors (specimens SP5_C, SP6_L). Results are compared in terms of stresses vs. the acquisition time. Both the sensors and the machine load cell recorded one data per second, so the two data sets are overlapped in the same diagram. The comparison between sensors readings and the reference stresses evaluated by the load cell have shown quite good matching both in the preloading phase and in the monotonic load phase up to the peak stress.

However, moderate discrepancies were also revealed, for instance, sensors placed in specimen SP5_C seem to measure lower stresses with respect to those actually occurring. This was manly observed in correspondence of the lower load levels (before $1000 \mathrm{sec}$ ). Better accordance was found for specimen SP6_C and bricks masonry. 
L. La Mendola, M.C. Oddo, M. Papia, F. Pappalardo, A. Pennisi, G. Bertagnoli, F. Di Trapani, A. Monaco, F. Parisi and S. Barile
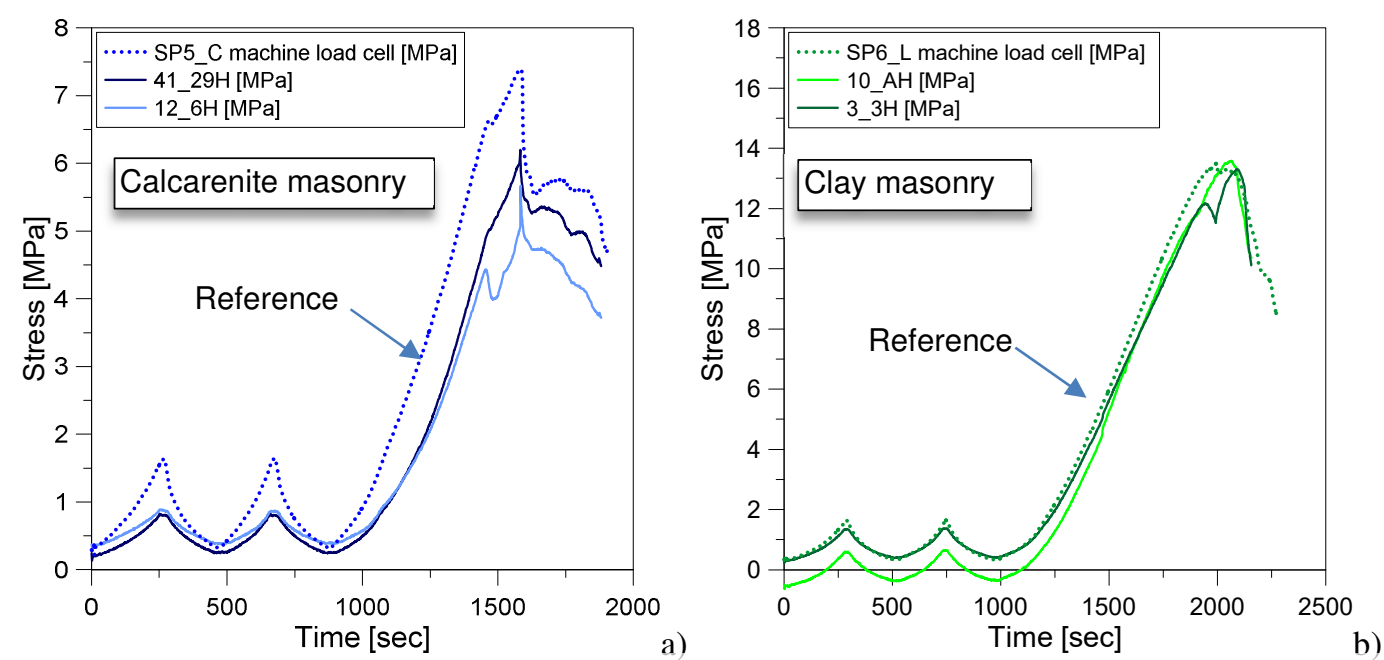

Figure 4: Comparison between ceramic stress sensor results and load cell data: a) calcarenite masonry; b) clay masonry.
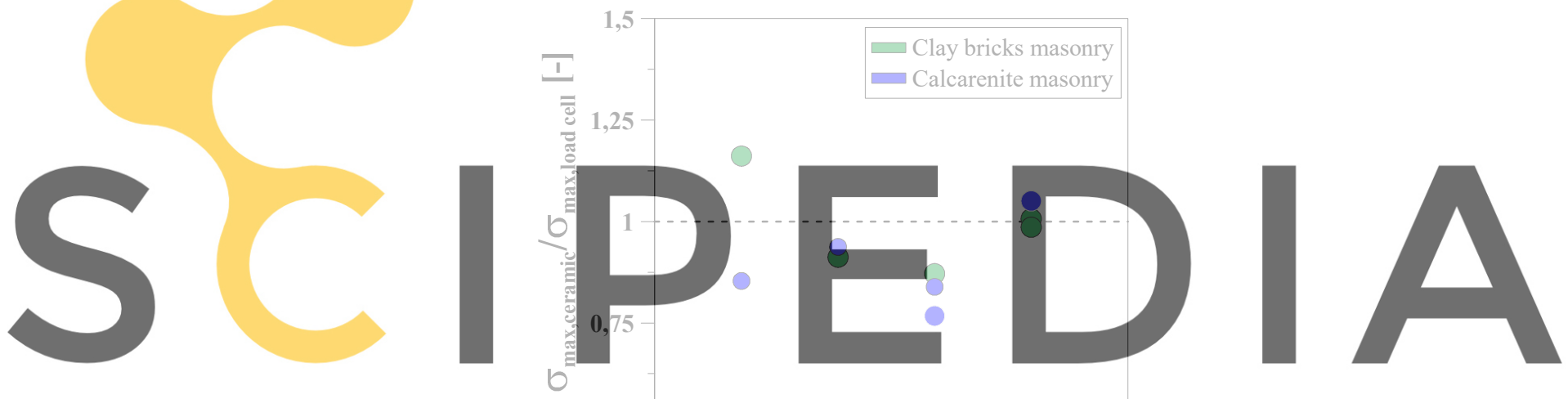

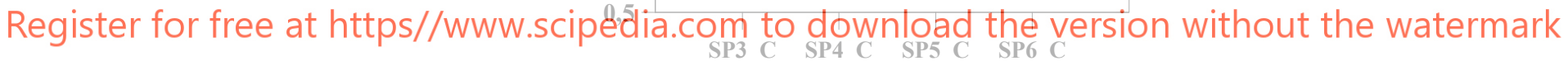

\section{Specimen}

Figure 5: Comparison between reference compressive strengths and maximum stresses recorded by ceramic stress sensors for calcarenite and clay brick masonry specimens.

In Table 2 the values of the maximum compressive strengths provided by the ceramic stress sensors $\left(\sigma_{\text {max,ceramic }}\right)$ are also shown and compared to those recorded by the machine load cell $\left(\sigma_{\max , l o a d}\right.$ cell $)$ for all the specimens (not only those shown Figure 4$)$.

Figure 5 summarizes the ratios between compressive strength recorded by ceramic stress sensors $\left(\sigma_{\text {max,ceramic }}\right)$ and reference compressive strength $\left(\sigma_{\max , \text { load cell }}\right)$, highlighting a limited scattering of results with an average underestimation of $15 \%$ and $7.7 \%$ and an average overestimation of $5 \%$ and $8.4 \%$ for calcarenite and brick masonry specimens, respectively. 
L. La Mendola, M.C. Oddo, M. Papia, F. Pappalardo, A. Pennisi, G. Bertagnoli, F. Di Trapani, A. Monaco, F. Parisi and S. Barile

Table 2: Compressive strengths of specimens by ceramic sensors and load cell.

\begin{tabular}{|c|c|c|c|c|c|}
\hline Specimen & $\begin{array}{c}\sigma_{\mathrm{max}, \text { load cell }} \\
(\mathrm{MPa})\end{array}$ & $\begin{array}{c}\sigma_{\max }, \text { load cell } \\
\text { Avg. / STD } \\
\text { (MPa) }\end{array}$ & & & $\begin{array}{c}\sigma_{\max }, \text { ceramic } \\
\text { Avg. / STD } \\
\text { (MPa) }\end{array}$ \\
\hline SP3_C & 6.96 & \multirow{4}{*}{$7.01 / 0.37$} & & & \multirow{4}{*}{$6.38 / 1.32$} \\
\hline SP4_C & 7.19 & & & & \\
\hline SP5_C & 7.39 & & 6.20 & 5.67 & \\
\hline SP6_C & 6.52 & & 6.87 & 6.85 & \\
\hline SP3_L & 12.46 & \multirow{4}{*}{$13.8 / 0.51$} & \multirow{2}{*}{\multicolumn{2}{|c|}{$\begin{array}{l}14.47 \\
12.42\end{array}$}} & \multirow{4}{*}{$13.48 / 0.74$} \\
\hline SP4_L & 13.62 & & & & \\
\hline SP5_L & 15.63 & & 13.62 & $*$ & \\
\hline SP6_L & 13.50 & & 13.59 & & \\
\hline
\end{tabular}

*data considered unrealistic.

\subsection{Results by capacitive sensors}

For the sake of space, a reduced number of test results are presented in the following. Figures $6 \mathrm{a}$ and $6 \mathrm{~b}$ show results for calcarenite and clay brick masonry respectively, equipped with capacitive stress sensors (SP1_C, SP2_C, SP1_L, SP2_L). In Fig. 6, experimental data by sensors are plotted against two vertical axes, that is the axis of vertical stresses, referred to data recorded by the testing machine load cell and the axis of capacitance, referred to data recorded

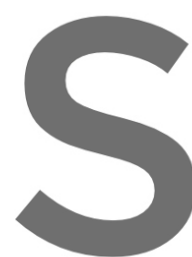
by capacitive stress sensors. The sampling frequency of data by capacitive sensors was 2 Hz,
that is two times that of the testing machine. To ensure the consistency of the two
measurements, capacitive sensors data are represented as one per second. Results from
capacitive stress sensors showed a stepped trend. This is related to the resolution limit of the
acquisition system. Despite measures by the sensors are referred to eapacitance values, it should observed that the global trend was correctly interpreted. This can be observed comparing stresses and capacitance trends in the two pre-load cycles, the ascending loading branch and

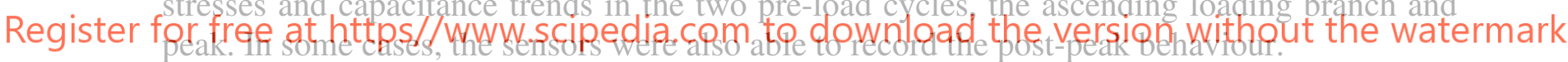

To date, results of measurements by capacitive stress sensors and stresses recorded by the load cell cannot be compared since, these sensors are still in a prototyping status and a reliabie transformation function from capacitance to stress has not been yet defined. Because of the same reason, experimental capacitance plots start from different values, in fact, the capacity of each device at zero deformation is different as the prototypes are hand-assembled. In some cases, the sensors also followed the load history with different slopes. This occurs because, as expressed by Eq. (1), the relationship between the capacitance and the electrode distance is nonlinear, implying that, for $\Delta d$ intervals the corresponding capacitance range $\Delta C$ varies in a significant way. 

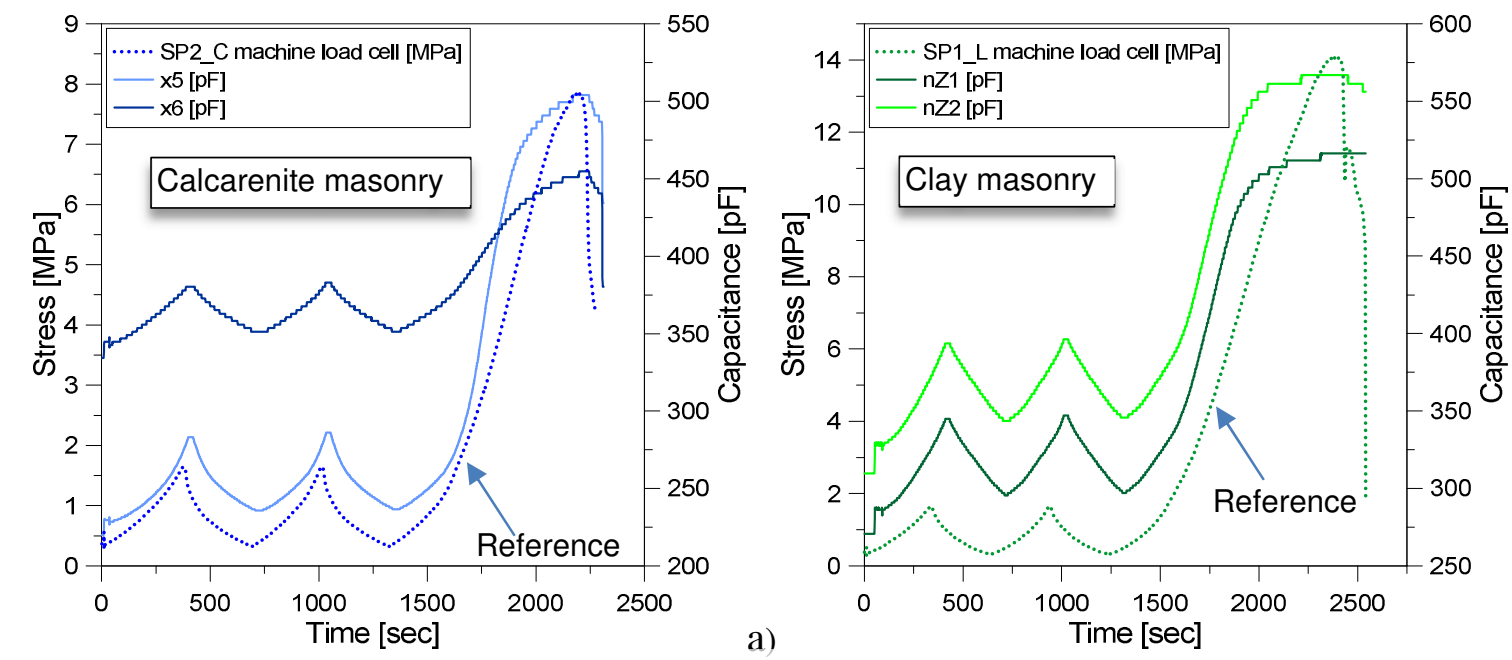

b)

Figure 6: Comparison between capacitive stress sensor results and load cell data: a) calcarenite masonry; b) clay masonry.

\section{5}

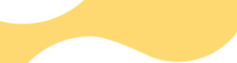

\section{CONCLUSIONS}

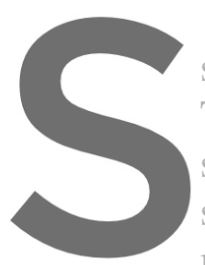

The paper presented sensors embedded in ma Two types of sensor sensor. Those monitorin structural elements, so t monitoring of masonry
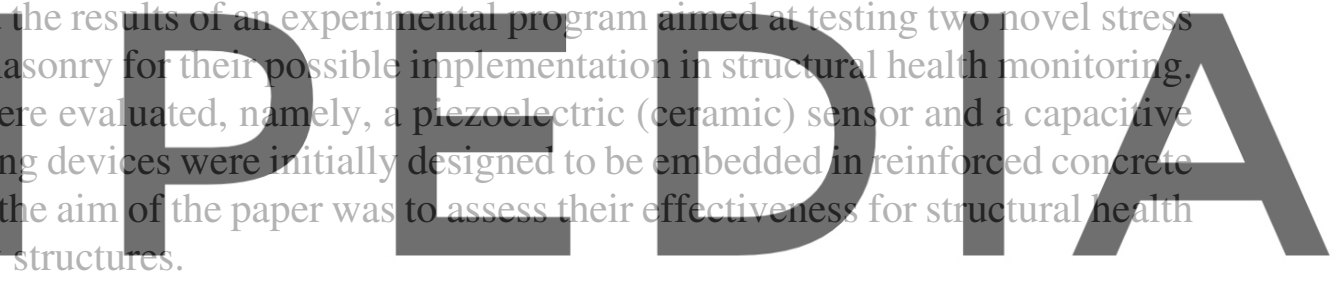

Experimental tests were carried out on twelve masonry specimens. Six of those specimens

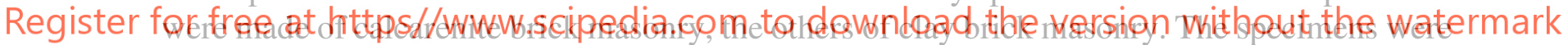
tested in simple compression after cyclic pre-loading phase. Peak strength varied from 6.52 to 8.21 $\mathrm{MPa}$ and 12.46 to $15.63 \mathrm{MPa}$, for calcarenite and clay brick masonries, respectively.

Results have highlighted that ceramic stress sensors have shown very good agreement with the stresses recorded by the load cell. Comparisons in terms of average peak stress evidenced a good accuracy, showing an underestimation of $10 \%$ in the case of calcarenite stone masonry and only $3 \%$ in the case of clay brick masonry. Moreover, standard deviations by sensor readings were lower than $1 \mathrm{MPa}$, also showing a limited dispersion despite the uncertainties related to the heterogeneity of masonry and potential local shortcomings of installation. Therefore, experimental results confirmed the suitability of ceramic sensors to be installed in masonry structures, without any need for additional calibrations with respect to that performed for the same sensors applied to concrete structures.

As regards capacitive sensors, since their calibration is still ongoing, results were compared in a more qualitative way. Sensor readings in terms of capacitance showed more pronounced correlation with recorded stresses up to a threshold of $9 \mathrm{MPa}$. After, a highly nonlinear relationship was observed, demonstrating that a full characterization is needed to define a robust analytical stress-capacitance relationship. It should be also noted that such a nonlinear 
relationship between capacitance and electrode distance is not necessarily a weakness, but a possible starting point to take into account when realizing a family of sensors with different load working ranges as a function of potential different applications. Finally, it is noteworthy observing that the tests here presented were carried out up to the achievement of the peak loads of masonry. However, the application of the stress sensors for SHM is generally related to serviceability load conditions. In this context, the better results obtained for the lower stress ranges indicate a promising SHM tool. Both ceramic and capacitive sensors showed a positive response, demonstrating their ability to be regularly implemented in SHM of new masonry structures and potentially also existing masonry structures.

Acknowledgements. This study was developed in the framework of PON INSIST (sistema di monitoraggio INtelligente per la SIcurezza delle infraSTrutture urbane) research project, which was funded by the Italian Ministry for Education, University and Research (Programma Operativo Nazionale "Ricerca e Innovazione 2014-2020", Grant No. ARS01_00913). The experimental tests were carried out in the Structures Laboratory of the University of Palermo and the support of the lab staff is gratefully acknowledged.

\section{REFERENCES}

[1] Sohn, H., Farrar, C.R., Hemez, F.M., Shunk, D.D., Stinemates, D.W., Nadler, B.R., Czarnecki, J.J. A Review of Structural Health Monitoring Literature: 1996-2001. Los Alamos National Laboratories, 2003. Structural health monitoring Vol. 90 . 2010. Balageas, D., Fritzen, C.P., Güemes. A. Structural health monitoring Vol. 90, 2010. Boller, C., Chang, F.K., Fujino, Y. Encyclopedia of Structum 2009. Farrar, C.R., Worden, K. Structural health monitoring: Johin Wiley \& Sons, 2012.

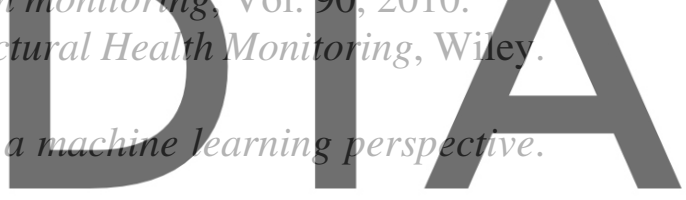

[5] Tokognon, C.A., Gao, B., Tian G.Y., Yan, Y. Structural health monitoring framework

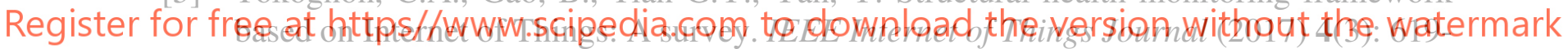
635.

[6] Dixit, S., Sharma K.A. Review of Studies in Structural Health Monitoring (SHM). In Creative Construction Conference (2019); pp. 84-88. Budapest University of Technology and Economics.

[7] Sony, S., Laventure, S., Sadhu, A. A literature review of next-generation smart sensing technology in structural health monitoring. Structural Control and Health Monitoring (2019) 26(3): e2321.

[8] Bertagnoli, G., Malavisi, M., Mancini, G. Large scale monitoring system for existing structures and infrastructures. IOP Conference Series Materials Science and Engineering (2019) 603(5): 052042.

[9] La Mendola, L., Oddo, M.C., Papia, M., Pappalardo F., Pennisi A., Bertagnoli, G., Di Trapani, F., Monaco, A., Parisi, F., Barile, S. Performance of two innovative stress sensors imbedded in mortar joints of new masonry elements. Construction and Building Materials (2021) 297: 123764. 
[10] Bertagnoli, G. (inventor). Safecertifiedstructures Tecnologia (Assignee). Method and investigation device for measuring stresses in an agglomerate structure, Patent No. WO2017/178985 A1, 2016.

[11] Abbasi, M., Bertagnoli, G., Caltabiano, D., Guidetti, E. (inventors). ST Microelectronics s.r.l. (Assegnee). Stress sensor for monitoring the health state of fabricated structures such as constructions, buildings, infrastructures and the like, Patent No. EP 3392637 B1, 2017.

[12] Anerdi, C., Gino, D., Malavisi, M., Bertagnoli, G. A sensor for embedded stress measure of concrete: Testing and material heterogeneity issues. In: Lecture Notes in Civil Engineering, 2020.

[13] Abbasi, M., Anerdi, C., Bertagnoli, G. An embedded stress measure of concrete: A new sensor able to overcome rheology issues. Proc, Italian Concrete Days 2020, Naples, April 2021.

[14] Pappalardo, F., Pennisi, A., Guidetti, E., Doriani, A. (inventors). ST Microelectronics s.r.l. (Assegnee) Capacitive pressure sensor for monitoring construction structures, particularly made of concrete, Patent n. US 10,914,647 B2, 2019.

[15] EN 1926. Natural stone test methods - Determination of uniaxial compressive strength, 2006.

[16] EN 772-1. Method of test for masonry units - Part 1: Determination of compressive strength, 2011.
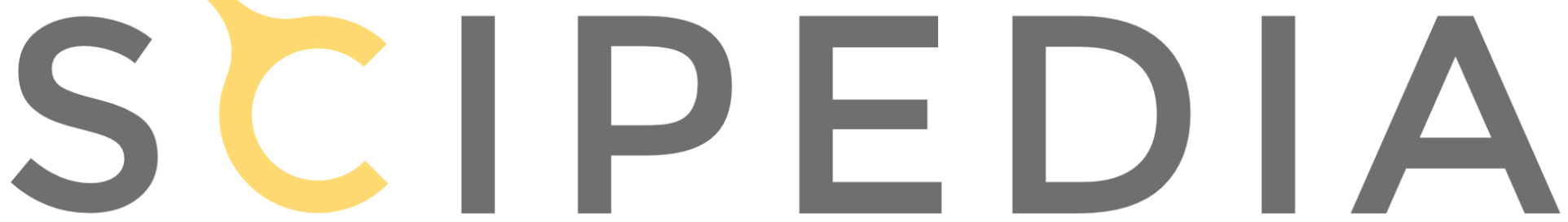

Register for free at https//www.scipedia.com to download the version without the watermark 